Klaus Hildebrand

\title{
Hitler. Rassen- contra Weltpolitik
}

Ergebnisse und Desiderate der Forschung

"The point cannot be stressed too strongly: Hitler was master in the Third Reich. « ${ }^{1}$ Mit diesen Worten bezieht der amerikanische Historiker Norman Rich, einer der besten Sachkenner der Geschichte des preußisch-deutschen Nationalstaates, Position in einer Auseinandersetzung über die Erheblichkeit des »Faktors Hitler « im Gefüge des "Dritten Reiches«. Anders als eine revisionistische Schule der Hitler-Forschung, die den "Führer « des nationalsozialistischen Deutschlands als "schwachen Diktator " ${ }^{2}$ darzustellen versucht und seine Außenpolitik und Strategie als Exponate »der antagonistischen Kräfte der entfesselten Gesellschaft des $2 D$ ritten Reiches “ ${ }^{3}$ begreifen möchte, unterstreicht Richs große Untersuchung über die deutsche Kriegsziel- und Besatzungspolitik im Zweiten Weltkrieg die ausschlaggebende Bedeutung der Persönlichkeit und Politik Hitlers für die Geschichte des "Dritten Reiches ", was insbesondere im Hinblick auf die Gestaltung der Außenpolitik Deutschlands bereits zeitgenössisch von Albrecht Haushofer so umschrieben worden war: »Der Führer selbst bestimmt die großen Züge der deutschen Außenpolitik. « ${ }^{4}$

Angesichts solcher Einsichten erscheint es sinnvoll, sich nicht jener mächtigen Tendenz der zeithistorischen Forschung anzuschließen und danach zu streben, unter $\mathrm{Zu}$ hilfenahme komplizierter Theorien zu beweisen, was historisch nicht zutreffend war, nämlich daß Hitler eine im Grunde austauschbare Figur des sogenannten »deutschen Faschismus « und seine Außenpolitik nichts weiter als ein Derivat wirtschaftlicher, gesellschaftlicher oder systemgeborener Bedürfnisse seines Regimes gewesen sei. Vielmehr soll das Augenmerk auf jene Probleme gerichtet werden, die Zeitgenossen und Historiker immer wieder beschäftigt und fasziniert haben. Sie kreisen im Grunde alle um das Rätsel der Persönlichkeit Hitlers und um die Fragen seiner Rassen- und Außenpolitik sowie seiner Strategie, die das Gesicht der Welt, die Innen- und Außenpolitik der Völker und Staaten im Grunde bis heute bestimmt und verändert haben. Denn während die Vorbedingungen der Entstehung des Nationalsozialismus in Deutschland vergleichsweise gut erforscht und bekannt sind und man ohne $Z$ weifel davon ausgehen kann, daß der Begriff des sogenannten "europäischen Faschismus « weitgehend vom politischen Existenzbedürfnis eines sogenannten "Antifaschismus « künstlich am Leben gehalten wird, der wissenschaftlichen Distinktion dagegen entbehrt, sind wesentliche Gravamina der Hitler-Forschung, die die Weltpolitik bis heute prägen, nach wie vor umstritten, wenn man an die Problematik der Endziele Hitlers und seiner Judenpolitik denkt oder wenn man Einzelheiten seiner England-, Rußland-, Japan- oder Amerikapolitik betrachtet. Den Ergebnisstand auf diesem Sektor der Geschichtswissenschaft zu spiegeln und einschlägige Desiderate der Historiographie zu formulieren, erscheint daher als sinnvolle Aufgabe eines Forschungsberichts.

\section{Standardwerke der Hitler-Forschung}

Trotz des kaum mehr überschaubaren Publikationsausmaßes der "Hitlerwelle ${ }^{5}$ kann die große Biographie über den Diktator von Alan Bullock ${ }^{6}$ nach wie vor als Ausgangspunkt aller wissenschaftlichen Bemühungen um das »Phänomen Hit/r« gelten. Obwohl der englische Historiker auch in der vollständig überarbeiteten Neuausgabe seiner "Studie über Tyrannei« die machiavellistischen Qualitäten des "Führers» herausarbeitet, vermag er doch keineswegs A. J. P. Taylors "Urteil über Hitler und seine Außenpolitik ... zu teilen«. (S. LX) Denn dieser hat den Diktator in seinem Werk 
über die Ursprünge des Zweiten Weltkrieges als einen von weltanschaulichen Voraussetzungen unabhängigen, reinen Machtpolitiker gezeichnet, der nicht anders als vor ihm Stresemann Revisionismus getrieben habe und von den Westmächten zum Krieg gezwungen worden sei. Vielmehr schätzt auch Bullock in Ubereinstimmung mit den Uberlegungen Trevor-Ropers das programmatische Element in Hitlers Gedankenbildung und Politik hoch ein, wenn er über die Entscheidung des „Führers«, im Sommer 1941 in die Sowjetunion einzufallen, schreibt: „Für seinen Entschluß, Rußland anzugreifen, gab Hitler damals zwei Gründe an: erstens sei Rußland im Begriff, für den Sommer 1941 einen Angriff auf Deutschland vorzubereiten, zweitens gebe England seine Niederlage nur darum nicht zu, weil es auf die Intervention der Russen und Amerikaner hoffe und tatsächlich bereits ein Bündnis mit Rußland gegen Deutschland geschlossen habe. Man könne also England nur schlagen, wenn man seine Hoffnung auf russische Hilfe zunichte mache. Diese Argumente dienten höchstens dazu, eine schon aus anderen Gründen getroffene Entscheidung zu bekräftigen. Hitler überfiel Rußland aus dem einfachen, aber hinreichenden Grund, daß er von jeher die Absicht hatte, durch Annexion des Gebietes zwischen Weichsel und Ural die Grundlagen für sein tausendjähriges Reich zu schaffen." (S. 637)

Bullocks Darstellung informiert über die Einzelheiten der Vita Hitlers vor dem Hintergrund der 20er, 30er und 40er Jahre des 20. Jahrhunderts, so daß mit seinem Buch im Grunde auch eine Geschichte des Nationalsozialismus vorliegt. Nicht zuletzt auch unter diesem Gesichtspunkt ist Bullocks Werk ebenso wertvoll, wie die kurzgefaßte Darstellung über den Nationalsozialismus von Helga Grebing ${ }^{7}$ unbeschadet mancher bestreitbarer Passagen informativ ist. Sie wird mittlerweile in der 18. Auflage benutzt und löst schon relativ früh manches heute in der Forschung wohl aus weltanschaulichem Vorverständnis umstrittene Problem ganz plausibel. So schreibt die Autorin z. B. über die noch immer umstrittene Frage nach der Stellung der Arbeiterschaft zum Nationalsozialismus und zum »Dritten Reich “, die gewiß deshalb die Gemüter bis heute erhitzt, weil nach wie vor dementiert wird, daß eine Affinität der "Arbeiterklasse « zum "Faschismus" bestanden habe: "Selbst ein großer Teil der Arbeiterschaft arrangierte sich mit dem >Dritten Reich «, besonders als sich seine soziale Situation nach dem Abklingen der Weltwirtschaftskrise und durch die mit der Aufrüstung erreichte Vollbeschäftigung gebessert hatte.« (S. 127-128)

Doch trotz aller Aufmerksamkeit, die der Geschichte des Nationalsozialismus geschenkt worden ist, konzentrierte sich das Interesse der Geschichtsschreibung immer wieder auf Hitler, ohne den die Existenz des Nationalsozialismus eine völlig andere Qualität erhalten hätte. In diesem Sinne kann die von $H u g h R$. Trevor-Roper ${ }^{8}$ kurz nach Kriegsende verfaßte, inzwischen in 3. Auflage vorliegende Studie über "Hitlers letzte Tage « nach wie vor Aufmerksamkeit beanspruchen. Vor allem dem Kapitel über Hitlers Umgebung während der letzten Phase des Weltkrieges, das Trevor-Roper "Hitler und sein Hof « überschrieben hat, verdankt die Forschung wichtige Einsichten in den Regierungsstil des Diktators. In dem Maße, in dem wir dabei über Bormanns Stellung unterrichtet werden, erkennen wir, wie abgeleitet dessen Kompetenzen im Grunde von der Macht Hitlers waren, die allgegenwärtig erscheint. Ihre Grenze fand sie wohl nur im Widerstand, den der Diktator von der ihm enteilenden Zeit erfuhr. Denn sie war es, die den "Führer " vor allem in den Jahren zwischen 1937 und 1942 vor sich her jagte, seine kalkulierenden Überlegungen verwirrte und das "Programm « des Diktators zerstörte, seine weiträumig entworfenen Ziele in getrennt zu führenden Blitzkriegen und unter Vermeidung des Risikos einer $Z$ weifrontenauseinandersetzung zu verwirklichen. Ansonsten aber scheint Hitlers Allmacht, sieht man von den letzten Monaten des Krieges einmal ab, unbestritten gewesen zu sein. Daher mag einer Richtung der Forschung, die Hitler jetzt auf das Normalmaß eines imperialistischen Politi- 
kers im Dienste gesellschaftlicher Systembewahrung reduzieren möchte, vorgehalten sein, was Trevor-Roper bereits vor 30 Jahren treffend ausgeführt hat: "Emigranten, marxistische Theoretiker und verzweifelte Reaktionäre haben vorgegeben oder sich selbst eingeredet, daß Hitler selbst nur eine Schachfigur in einem Spiel war, das nicht er spielte, sondern einige andere Politiker oder gewisse kosmische Kräfte. Das ist ein fundamentaler Irrtum. Welche unabhängigen Kräfte immer er benutzt, welch zufällige Unterstützung er sich geborgt haben mag, Hitler blieb bis zum Schluß der alleinige Herr und Meister der Bewegung, der er selbst Leben eingehaucht, die er selbst gegründet hatte und die er selbst, durch seine persönliche Führerschaft, vernichten sollte. « (S. 70) Und in dem gleichen Maße, in dem Trevor-Roper Hitler win den Frühtagen des Nazismus* (S. 218) politisches Genie zubilligt, so klar erkennt er eines der Endziele des Diktators, denen das sogenannte Genie ebenso diente wie die sogenannte Modernität, die den Nationalsozialismus über weite Strecken charakterisierte (S. 218): "Sein letztes Ziel war freilich allen jenen klar, die sich nicht willfährig selbst belogen: Er steuerte auf die Zerstörung der europäischen Zivilisation durch ein barbarisches Imperium in Mitteleuropa los, auf die furchtbare Hegemonie eines neuen, bleibenden Dschingis-Khan, auf , ein neues Mittelalter،, wie Churchill es nannte, , noch mehr verfinstert, und vielleicht auch verlängert, durch die Erleuchtungen einer pervertierten Wissenschaft $<$ «

Damit hat Trevor-Roper in nuce bereits unmittelbar nach Kriegsende die bis heute die Forschung beschäftigende Frage nach dem Verhältnis von modernen und archaischen Elementen im »Faschismus « mit Hinblick auf den "Hitlerismus « überzeugend beantwortet. Ausgefeilte Modernität stand im Dienste einer vormodernen Vision, die danach strebte, den Verlauf der Geschichte außer Kraft zu setzen, ihn in eine rassische Utopie zu überführen und Weltgeschichte in einen biologischen Stillstand einmünden zu lassen. Eben um diese Probleme kreist nicht zuletzt auch die jetzt wieder aufgelegte und um einige politisch aktuelle Aperçus angereicherte Studie von Gert Kalow ${ }^{9}$ über "Hitler - das deutsche Trauma *. Dadurch, daß der Autor sich davor fürchtet, der "Personalisierung komplexer historischer Fragen" und somit der "Gefahr einer neuerlichen Regression auf ein magisches Weltbild « zu erliegen, wie es in der Ankündigung des Verlages lautet, wird in Kalows geistreichen Spekulationen, die große Belesenheit in der europäischen Geistesgeschichte verraten, in den einschlägigen Fragen der Hitler-Forschung aber weniger gut bewandert scheinen, niemals recht klar erkennbar, was Hitler denn nun mit der lebhaft beklagten idealistischen Tradition, deren "Pest weiter (umgehe) und . . ganze Völker verschlinge" (S. 13), mit dem Nationalsozialismus und mit dem "Faschismus eigentlich verbindet und worin er sich von allen diesen Phänomenen unterscheidet.

Dabei läßt sich die Erscheinung des "Faschismus« ja noch durchaus als eine Gegenbewegung der sich herausgefordert fühlenden »bürgerlichen "Welt gegen den kommunistischen Revolutions- und Weltherrschaftsanspruch mit der historischen Verstehenskategorie erfassen und bestimmen. Ebenso ist im Grunde das Zustandekommen der je nationalen "Faschismen « - so z.B. des Nationalsozialismus - erklärbar, wenn man die spezifischen historischen Vorbedingungen des jeweiligen Nationalstaates analysiert, die neben der allgemein verbindlichen kommunistischen Herausforderung im besonderen ausschlaggebend wirkten, und wenn man sie durch einen vergleichenden Blick auf das Úberleben des ja ebenfalls generell gefährdeten britischen Parlamentarismus deutlich konturiert. Seine eigentlich historisch relevante Entfaltung aber erfuhr der Nationalsozialismus durch Hitler, und eben der Fall Hitler« stellt die traditionelle Geschichtswissenschaft auf eine nur schwer lösbare Probe. Die machtpolitischen Elemente der Weltpolitik des Diktators erscheinen ihr dabei noch in einem hohen Maße erkennbar und verständlich, so z.B. sein Grundplan, zusammen mit Eng- 
land das bolschewistische Rußland Stalins im Schach zu halten bzw. zu zerschlagen. Und solange sein Antisemitismus innenpolitischer Herrschaftsgewinnung und -konsolidierung diente, glich er im Grunde jenen in der europäischen Geschichte bekannten Methoden, durch Instrumentalisierung eines Feindbildes Massen zu bewegen und Macht zu erhalten. Seine global angelegte Rassen- und Eroberungspolitik aber besaß jene Eigenständigkeit, die alle als opportun diskutierbaren machtpolitischen Kalkulationen zerstörte. Hier beginnen nun die Verstehensprobleme, die die Geschichtswissenschaft nach wie vor beschäftigen und die sich - am Beispiel veranschaulicht - aus der Sicht Großbritanniens in den Anfangsjahren des Zweiten Weltkrieges so ausnahmen: Konnte England, nachdem man im Foreign Office und im Kabinett wohl schon gegen Ende der 30er Jahre mehr und mehr von Hitlers global orientierter politischer Zielsetzung erfuhr und überzeugt war, dennoch mit dem Deutschen Reich zusammenarbeiten, ihm Kontinentaleuropa völlig überlassen und versuchen, selbst im Besitz des weltumspannenden Empire den "Führer « gegen Stalin auszuspielen, als tertius gaudens die nationalsozialistische sowie die kommunistische Gefahr zu neutralisieren und dadurch nicht zuletzt von jener amerikanischen Hilfe frei zu bleiben, die sich ja schon so bald zur Ablösung Großbritanniens als der führenden Weltmacht durch die Vereinigten Staaten auswuchs? War Churchills Entscheidung grundsätzlich richtig, in den Jahren 1940-1941 den Friedensschluß mit Hitler zu vermeiden, da der Premierminister davon ausging, daß dem Erwerb der kontinentalen Hegemonie Deutschlands Griff nach einer überseeischen Weltmachtstellung folgen würde und er dabei um den Bestand des britischen Empire, der freiheitlichen Institutionen seines Landes und des englischen "way of life « fürchtete? Oder erscheint nicht in einer längerfristigen Perspektive betrachtet und angesichts des hohen Preises, den England für seinen Sieg im Zweiten Weltkrieg bezahlte, Chamberlains Appeasementpolitik wiederum in einem vorteilhafteren Licht? Konnte London nicht unbeschadet der britischen Erkenntnisse über Hitlers Rassen- und Weltpolitik ausharren, Kompromisse schließen und warten, ob der Diktator sich nicht doch einmal abnutzen und sich die Chance ergeben werde, mit einem Deutschen Reich zusammenzuarbeiten, in dem dann vielleicht ein Repräsentant wie Hermann Göring regieren und das der global orientierten Eroberungspolitik Hitlers, wenn auch nicht seines großmächtlichen Anspruchs in Mitteleuropa sowie des antikommunistischen Charakters seiner Außenpolitik entbehren mochte? Der Niedergang des englischen Weltreiches wäre unter solchen Bedingungen wohl kaum so rapide verlaufen, der britische Parlamentarismus dabei weniger in Mitleidenschaft gezogen, Stalin an seinen weiträumigen, durch den Zweiten Weltkrieg ermöglichten Expansionen wohl gehindert worden und die Abhängigkeit Englands von den USA erträglicher gewesen.

Alle diese bis heute nachwirkenden Probleme der Weltpolitik jener Zeit aber kann man nur dann erörtern, wenn man sich von einer Identifizierung Hitlers mit dem facettenreichen, mannigfache politische Alternativen bietenden Phänomen des Nationalsozialismus bzw. gar mit dem Terminus vom »Faschismus « löst. Der sogenannte »Faschismus « und der Nationalsozialismus sind funktionaler Interpretation und der historischen Verstehenskategorie zugänglich. Das Ausmaß und die Widersprüchlichkeit der Rassen- und Weltpolitik Hitlers aber präsentierten der britischen Führung im Zweiten Weltkrieg jene umfassend kaum zufriedenstellend zu lösende Schwierigkeit, die Endziele des Diktators fürchten und sich um der Bewahrung des Empire willen mittelfristig doch mit ihm arrangieren zu müssen, ohne ihm machtpolitisch und moralisch auf die Dauer zu verfallen ${ }^{10}$. Eben diese Fragen zu beantworten, die der "Fall Hitler « bis heute immer wieder aufwirft, ist der Geschichtswissenschaft nach wie vor als Aufgabe gestellt. 


\section{Unverzichtbare Details?}

Fast ausnahmslos dem Untersuchungsgegenstand »Hitler « gewidmet sind die zahlreichen Arbeiten von Werner Maser, der die Summe seiner ungemein detailliert geführten Nachforschungen in seiner Hitler-Biographie ${ }^{11}$ zusammengefaßt hat, die mittlerweile in der 6. Auflage vorliegt. Sie kann als ein Nachschlagewerk der Hitler-Forschung gelten, allerdings nicht den Anspruch einer klassischen Biographie erheben. Wesentliches und Unwesentliches, ausschlaggebend Politisches und nebensächlich Privates stehen nebeneinander und stören den Eindruck eines Gesamtbildes. Dabei liest man Masers Ausführungen über Hitlers Krankheitssymptome, über seine eingebildete und tatsächliche Zeitnot, die ihn so grundsätzlich von seinem Gegenspieler Stalin unterschied, und über deren Auswirkungen auf Politik sowie Strategie des Diktators mit großem Interesse, da damit ein noch nicht genügend erforschtes Thema der Zeitgeschichte angesprochen wird: "Die Vorstellung, krank zu sein und nur noch wenig Zeit zu haben, beherrscht alles, was Hitler seitdem (nämlich 1937) denkt, plant und tut. * (S. 375) Ja, in diesem Zusammenhang ist es interessant, Werner Masers Stellungnahme zu dem wohl entscheidendsten und in seinen Einzelheiten nach wie vor umstrittenen Problem in der Geschichte des Nationalsozialismus, zur Judenvernichtung, kennenzulernen. Denn die "Endlösung ", das damit in Verbindung stehende "Euthanasieprogramm " und die entsprechenden "Züchtungsmaßnahmen " des Regimes bedürfen erst noch ihrer gründlichen und umfassenden Darstellung. "In diese Zeit (Anfang (!) 1941)“, so schreibt Maser im Hinblick auf die nationalsozialistische Judenpolitik im Zweiten Weltkrieg, "fallen auch die Weisungen für die ,Endlösung der Judenfrage in Europar. Am 2. April 1941 hat Hitler Rosenberg bei sich zu Gast. Mit ihm spricht er über Dinge, die Rosenberg nicht einmal in sein Tagebuch aufzunehmen wagt. > Was ich heute nicht niederschreiben will, aber nie vergessen werde`, notierte er nach der zweistündigen Unterredung mit Hitler, der ihn offenbar über seinen Plan der Ermordung der Juden informiert hat. Am 20. Mai 1941 ist bereits Adolf Eichmanns Referat IV B 4 über die sunmittelbar bevorstehende Endlösung der Judenfrage informiert, das sämtliche Staatspolizeistellen im Reich und in Frankreich anweist, die Auswanderung der Juden aus Frankreich und Belgien zu unterbinden und sim Hinblick auf die unmittelbar bevorstehende Endlösung der Judenfrage die letzten Passagemöglichkeiten für die Auswanderung von Juden aus dem Reich offenzuhalten. “(S. 378)

Wandte sich Werner Maser ${ }^{12}$ in seiner 1973 veröffentlichten, nunmehr unter dem Titel "Der Sturm auf die Republik " neu aufgelegten Studie, die inzwischen durch die eingehende Untersuchung von Albrecht Tyrell ${ }^{13}$ über den "Wandel von Hitlers Selbstverständnis zwischen 1919 und 1924 und die Entwicklung der NSDAP« überholt sein dürfte, der "Frühgeschichte der NSDAP « zu, so hat sich sein Interesse doch schon bald ganz auf die Persönlichkeit Hitlers konzentriert. Er publizierte Hitlers Briefe und Notizen ${ }^{14}$, die die Forschung aber kaum weiterführen und auf deren fragwürdige Editionspraxis an anderer Stelle aufmerksam gemacht worden ist ${ }^{15}$. Werner Maser ${ }^{16}$ veröffentlichte ferner eine Arbeit über Hitlers "Mein Kampf ", in der sich die Geschichte des unbeachteten Bestsellers ebenso wie Auszüge und Kommentare aus dem HitlerBuch finden, und der er den irreführenden Untertitel "Fahrplan eines Welteroberers « gab. Denn die heuristisch von Andreas Hillgruber so fruchtbar in die Erörterung der Hitler-Forschung eingeführte Interpretationsfigur des Stufenplans, wonach der Diktator daran dachte, zu seinen Lebzeiten ein Kontinentalimperium einschließlich der anvisierten russischen Territorien zu erobern, sodann überseeische Ergänzungsräume zu erwerben, später lebende Generationen auf den Kampf gegen die USA vorzubereiten und in globalem Maßstab Rassenherrschaft zu verwirklichen, ist kaum mit 
"Mein Kampf « könnte die Forschung ebensogut verzichten wie auf die entsprechende kommentierte Auswahl aus »Mein Kampf «, die Christian Zentner ${ }^{17}$ vorgelegt hat. Uberflüssig erscheint auch ein von Maser ediertes sogenanntes Tagebuch »Mein Schüler Hitler«. Es enthält belanglose Aufzeichnungen, die der Schauspieler Paul Devrient $^{18}$ gemacht zu haben scheint, als er Hitler im Jahre 1932 Rhetorik-Unterricht gegeben haben soll.

Von der "Hitlerwelle« auf den Markt gespült und als wertloses Treibgut anzusehen, sind auch die von Walter Kempowski ${ }^{19}$ gesammelten "deutschen Antworten " auf die Frage "Haben Sie Hitler gesehen "? Sie sind weder aufschlußreich noch für den Sachkenner überraschend. Auch Sebastian Haffners Nachwort über "Die Deutschen und Hitler ", das wohl als "Dessert " zum faden "Hauptgang " locken soll, bringt nichts, was originell wäre.

Anders verhält es sich dagegen mit den zeitgenössischen Urteilen über den Diktator, die Philipp W. Fabry ${ }^{20}$ unter dem Titel »Mutmaßungen über Hitler* zusammengestellt, eingeleitet und kommentiert hat. Der Schwerpunkt der gesammelten Stimmen liegt in den Jahren 1930-1933, und diese spiegeln die zeitgenössische Orientierungslosigkeit in der Einschätzung Hitlers und des Nationalsozialismus wider. Besonders die zwischen Bewunderung und Abneigung hin- und herschwankenden Meinungen der ausländischen Staatsmänner und Diplomaten in den 30er Jahren kennenzulernen, ist insofern wichtig, um ihre Reaktionen auf Hitlers Politik verstehen zu können. Sicherlich kann man sich Fabrys, von Golo Mann übernommenem Urteil nicht anschließen, demzufolge Hitlers Streben nur einem Zweck gedient habe, nämlich *der Befriedigung seines Machttriebes« (S. 247). Vielmehr traf der konservative Gegner Hitlers, Ewald v. Kleist-Schmenzin, die Intentionen des "Führers", als er bereits vor der "Machtergreifung « schrieb, der Staat habe nach Hitlers Auffassung nicht die Aufgabe, "Fähigkeiten zu erzeugen, sondern nur, die rassische Anlage zu pflegen! Damit entwürdigt er den Staat zu einem Zuchtwart und zeigt, daß er unfähig ist, Wesen und Pflichten des Staates auch nur zu begreifen. « (S. 146) Ja, unter der Tarnung der " pazifistischen Platte " (S. 242), von der Hitler 1938 sprach, als er die Umstände beschrieb, die ihn seinem Selbstverständnis nach dazu zwangen, "jahrzehntelang fast nur vom Frieden zu reden", um seine Ziele "mit Mitteln der Gewalt « (S. 242) endlich verwirklichen zu können, schickte sich der Diktator an, seine Rassen- und Weltpolitik in die Wege zu leiten, die die Geschichte zu überholen vorhatte und in die ewige Ruhelage einer Rassenutopie zu versetzen gedachte. Tatsächlich gelang es ihm, seinem Ziel so nahe zu kommen, daß sich die Geschichte an den Abgrund geführt sah und die Zivilisation auf einem schmalen Grat wandelte, bis jener Gegenschlag einsetzte, den der merzkonservative« Regimegegner Friedrich Percyval Reck-Malleczewen mit der Hoffnung des Verzweifelten beschrieb, der allein schon um des eigenen Úberlebens willen dem Gang der Geschichte Sinn beimißt: »Geschichte duldet es wohl manchmal, daß der Gernegroß an den Hebeln ihrer Maschinerie herumspielt, sie duldet es eine Weile und scheint sich nicht zu regen. Bis plötzlich ihr Räderwerk sich dennoch in Bewegung setzt und zu rasen beginnt, und schließlich zermalmt es den Vorwitzigen. «21

Allein, trotz einer Fülle von teils wertvollen, teils überflüssigen Details, die die Hitler-Forschung zusammengetragen hatte, mußte man bis vor kurzem auf Alan Bullocks Biographie als Standardwerk zurückgreifen, wenn es darum ging, sich umfassend über Aufstieg und Fall Hitlers zu informieren. Inzwischen hat der englische Historiker Konkurrenz erhalten, die ihm ebenbürtig ist, ohne ihn verdrängen zu können, mag sie ihri auch in nicht unwesentlichen Einzelheiten der Darstellung korrigieren und im Reflexionsvermögen wohl übertreffen. Es ist Joachim Fest zu verdanken, daß es uns mittlerweile möglich ist, das "Phänomen Hitler « in seinen verschiedenen Dimensio- 
nen, in seiner deutschen, europäischen und globalen Perspektive verständlich zu machen. Carl Friedrich v. Weizsäcker ${ }^{22}$ hat sich dieser Aufgabe unlängst unterzogen und dabei die Frage nach Hitlers politischen Endzielen so beantwortet: „Das läßt sich mit wenigen Worten sagen, denn er war trotz taktischer Verschleierungen erstaunlich offen darüber: Es war die Weltherrschaft der nordischen Rasse, gestützt auf ein deutsches Reich im russischen Raum.«(S. 29)

\section{Joachim Fests Hitler-Bild}

Die Hitler-Biographie von Joachim Fest ${ }^{23}$ ist nicht zuletzt dadurch ausgezeichnet, daß es dem Autor gelungen ist, sich durch das Labyrinth der bislang vorgetragenen Deutungen zum "Fall Hitler " hindurchzufinden und die gegenwärtig in der internationalen Geschichtswissenschaft anstehenden Probleme der Hitler-Forschung so weit zu klären, daß nunmehr das für längere Zeit gültige Buch über Adolf Hitler vorliegen dürfte. Zu solchem Urteil regt weniger das Material der herangezogenen Quellen an, die allesamt durchaus bekannt sind. Vielmehr ist es die Virtuosität der Interpretation und die Kunst der Darstellung, die Fests Buch auszeichnen. Sie machen die oftmals nur mühsam lesbaren Detailanalysen der Historiker in glänzender Synthese verfügbar und wecken die Erinnerung daran, daß Geschichtsschreibung auch eine Kunst sein kann und Clio eine Muse ist.

Es sind in erster Linie die Kategorien des Autors, seine Denkmuster und Begriffe, mit denen er versucht, Individuum und Epoche zueinander in Beziehung zu setzen, die dieses Werk als ein Stück großer Geschichtsschreibung erscheinen lassen. Der vergleichende Blick auf andere Gesellschaften des kontinentalen Europa macht dieses Verfahren, Biographie als Zeitgemälde zu schreiben, noch einleuchtender.

Allerdings fehlt im Rahmen solch komparatistischer Prozedur die Betrachtung der vom Kontinent so verschiedenartig verlaufenden Entwicklung Großbritanniens. Eine Berücksichtigung dieses historischen Beispiels hätte jedoch sehr wahrscheinlich jenes Kriterium einer nichtidentischen Identität Hitlers mit der bürgerlichen Welt, das Fest als für Vita und Politik seines biographischen Objekts verbindlich herausarbeitet und Hitler in diesem Sinne als "den paradoxen Parteigänger des Approbierten, der eine Ordnung verteidigte, die er zugleich verwarf« (S. 57), charakterisiert, im Hinblick auf die politischen Artikulationsmöglichkeiten eben jener bürgerlichen Welt differenziert. Noch stärker, als Fest dies tut, hätte sie nämlich das Interesse auf die spezifisch preußisch-deutschen Vorbedingungen der Diktatur Hitlers gelenkt, die sich als »Verwerfungen « im preußisch-deutschen Gesellschafts-, Verfassungs- und Nationalgefüge niederschlugen und sodann im Zuge der Reaktion der bürgerlich-parlamentarisch organisierten Welt auf die kommunistische Herausforderung nach dem Ersten Weltkrieg in Deutschland maßgeblich zum Aufstieg der nationalsozialistischen »Bewegung « beitrugen. England dagegen ging aus historischen, politisch, wirtschaftlich und sozialpsychologisch erklärbaren Gründen einen ganz anderen Weg nationaler Geschichte, der den sogenannten "Faschismus « als Entwicklungsstadium vermeiden konnte, weil sein kaum in Frage gestelltes politisches System auf die Erfordernisse des Industrialisierungsprozesses durch modernisierende Reform im Rahmen parlamentarischer Institutionen, nicht aber durch starres Festhalten am politischen Status quo reagierte. In England, jenem kapitalistischen und bürgerlichen Land par excellence, konnte gerade nicht jene "faschistische Grundfigur " geschichtswirksam werden, die Fest in seinem magnum opus als eine der grundlegenden Kategorien des Hitler-Verständnisses herauspräpariert. Vor dem Hintergrund einschlägiger Einzeluntersuchungen gelingt es ihm, mit Hilfe dieses Begriffs plausibel zu machen, daß faschistische Bewegungen stets nur dann zur Macht gelangen können, wenn etablierte Eliten und amtierende Regie- 
rungen innerhalb eines Nationalstaates von antidemokratischer bzw. antiparlamentarischer Räson geleitet, entsprechende Hilfestellung leisten oder in politischer Abstinenz zum Geschehen verharren.

Fests Interpretation wird aber bezeichnenderweise dann unscharf, wenn er die Kategorie der "faschistischen Grundfigur « aufs Feld der internationalen Politik überträgt und unter diesem Aspekt die britische Appeasement-Politik zu begreifen versucht. Gewiß sind Phasen der Kooperation bzw. der Bemühung um Zusammenarbeit zwischen dem »faschistischen « Deutschland und dem »kapitalistischen « Großbritannien nicht zu übersehen, sicherlich ist das Motiv des Antikommunismus einer unter mannigfachen anderen Faktoren im Geflecht der Appeasement-Politik, die aus einer ganz anderen und viel älteren Tradition der äußeren Friedenssicherung und der inneren Reformpolitik Großbritanniens lebte und die sich Hitler ja letztlich auch verweigerte, als er die Komplicenschaft Englands suchte. Hier scheint die Grenze jener phänomenologisch und weltanschaulich prozedierenden Interpretierbarkeit des sogenannten "Faschismus« erreicht zu sein. Fests über weite Strecken hin hellsichtig erklärende, indes zu allgegenwärtig applizierte Kategorie der »faschistischen Grundfigur « wirft als Erklärungsmuster jedoch selbst noch in ihrem Scheitern an der Nahtstelle von innerer und äußerer Politik aufs Neue und prinzipiell die Frage nach wissenschaftlichem Sinn und analy tischer Tragfähigkeit des Faschismusbegriffs überhaupt auf. In seiner Fragwürdigkeit aber weist der immer bestreitbarer sich darstellende Begriff des sog. „Faschismus « vielmehr über sich hinaus und legt es nahe, zum Verständnis einer geschichtlichen Epoche, ihrer kollektiven Angst und ihres aggressiven Weltheilungsdranges, eine vergleichsweise so autonom handelnde Persönlichkeit, wie Hitler es war, als den Repräsentanten und Ưberwinder seiner Zeit ins Auge zu nehmen.

Als Revolutionär gegen die Revolution - so begreift eine weitere, grundlegende Kategorie Joachim Fests das »Phänomen Hitler « - kämpfte der deutsche Diktator mit modernen Mitteln gegen die moderne Zeit, lebte er mit seiner Epoche im Einklang und repräsentierte doch ihre schrillste Dissonanz, stand er durchaus in einer nationalen Kontinuität deutscher Geschichte und markierte doch deren Bruch mit ihrer Tradition. In dieser Perspektive erklärt Fest aus der "grande peur « vor dem Umsturz, die die Epoche und in ihr die Deutschen befallen hatte, die Weltherrschaftsziele Hitlers, der aus Angst um den Bestand von »Volk « und »Rasse « letztlich die Welt unterwerfen und rassisch zu erneuern trachtete. Dabei nimmt Fest - und dies ist ihm als einem Intellektuellen von Rang deswegen hoch anzurechnen, weil diese Prozedur wohl contre coeur der eigenen Empfindung stattgefunden haben mag - Hitler durchaus und zutreffend beim Wort und rümpft nicht in bildungsbürgerlichem Hochmut die Nase über die banalen und primitiven Gedanken des »Herrn $\mathrm{H} . \ll$, der eben meinte und tat, was er in seinen Programmschriften ausführte. Und so gelangt Fest endlich, die Probleme der gesellschaftlichen Basis und der sozialen Funktion des Nationalsozialismus ausführlich erörternd, aber eben darüber nicht - wie dies heute oftmals der Fall ist - die Frage nach den politischen Intentionen des Systems als die Frage nach den Zielen seines Diktators vernachlässigend, zu einer letzten, prinzipiell verbindlichen Kategorisierung Hitlers, die dazu geeignet ist, auch seine Erscheinung in die moderne Geschichte einzuordnen. Nicht ausdrücklich in die Modernisierungsdiskussion der Sozialwissenschaften eingreifend, von ihren Ergebnissen jedoch unübersehbar angeregt, zeichnet Joachim Fest, wie dies vor ihm Ralf Dahrendorf und David Schoenbaum getan haben, Hitler als Schrittmacher der Moderne wider Willen. Gerade der Mann, der durch Indienstnahme nahezu aller verfügbaren Mittel der Moderne, in eine mythische Zukunft agrarstaatlich und rassisch geprägter Ordnung vor-(bzw. zurück)dringen wollte, beschleunigte allerdings um den Preis bis dato unbekannt hoher menschlicher, sozialer und politischer (Un-)Kosten im letzten eben durch seinen Aufstand gegen die Ge- 
schichte mächtige Tendenzen ihrer Entwicklung, die er rückgängig zu machen bzw. zu tilgen versuchte.

In solcher Singularität Hitlers und seiner Ziele hebt sich der Diktator sodann als politische Persönlichkeit vom Nationalsozialismus oder vom "Faschismus « als Epochenphänomenen deutlich ab. Dies zu konstatieren, beinhaltet aber die Kritik, daß Fests begriffliche Bestimmung Hitlers als des faschistischen Typus seiner Zeit gerade im essentiellen Bereich seines Handelns, in seinem Aufstand gegen die Geschichte und die ihr innewohnende Transzendenz des Menschen, nicht mehr voll befriedigen kann. In der Repräsentation des kollektiv Verbindlichen steht Hitler in Kongruenz mit den Gefühlen, Ängsten, Sehnsüchten und Wünschen seiner Epoche; in der Artikulation und Verwirklichung seiner daraus resultierenden Zielvorstellungen aber ließ er alles Vergleichbare seiner Zeit weit hinter sich zurück. Es mag mit gewissen Mängeln des Verständnisses der Phänomene der internationalen Politik der Zwischenkriegszeit und des Zweiten Weltkrieges in dem vorliegenden Buch überhaupt zusammenhängen, daß Fest zwar grosso modo zutreffend, im einzelnen jedoch den Charakter und die Bedeutung der politischen Ziele Hitlers, die Welteroberung und die Rassenherrschaft, doch nicht ganz angemessen zu bewerten scheint. Dies könnte nicht zuletzt darin begründet liegen, daß sich im Feld der Außen- und Rassenpolitik die Chance der Vergleichbarkeit Hitlers mit anderen Faschismen und ihren Repräsentanten verflüchtigt. Wählt man z. B. Mussolini als "Faschisten « zum Parameter begrifflich angenommener Identität von Persönlichkeit und Bewegung, so ist doch kaum zu verkennen, daß seine Ziele und Mittel der äußeren Politik: des peso determinante, des kolonialen Imperialismus und der Restauration des römischen Weltreiches, im Grunde im vertrauten Kontext der Geschichte verharrten, während Hitlers Ziele eben diese Dimension des in manchem gewiß schrecklichen, aber immerhin historisch Bekannten zu sprengen suchten und er in diesem ganz wesentlichen Bereich seiner Politik und seines Handelns per definitionem nicht als Faschist charakterisiert werden kann.

Nicht nur die von Fest meisterhaft vermittelte Konturenlosigkeit des Hitlerschen Daseins als das des anonymen Massenmenschen, das Erschrecken vor einer kaum vorstellbar leeren Normalität, sondern entsprechend dazu die Maßlosigkeit seiner Ziele und der Schrecken angesichts einer nicht mehr historisch vorgestellten, sondern biologisch entworfenen Zukunft lassen Hitler endlich als "Unperson " erscheinen, d. h.: Kaum kann er noch als ein im Sinne der europäischen Tradition, wie sie sich in all ihren widersprüchlichen und vielfältigen Ausformungen als den Antworten und Reaktionen auf die Sinn- und Existenzfrage des "strebenden und leidenden Individuums " darbietet, handelnder Repräsentant begriffen werden. Dies zu erkennen, vermag auch zu erklären, warum Fest die Frage nach der historischen Größe Hitlers gar nicht beantworten konnte; denn sie ist im Prinzip an jene condition humaine gebunden, die im Falle Hitlers vom Unmaß des Banalen und des Bösen zerstört wurde und eben nicht darstellbar sein dürfte. Fest gelingt es zu zeigen, welche Möglichkeiten sich in einer welthistorisch wirksamen Figur, wie Hitler es war, verdichten können und als Gefährdungen der Geschichte und ihrer Träger, der menschlichen Spezies schlechthin, zu wirken imstande sind - mag Hitler auch letztlich durch seine radikale Revolte gegen alles Bestehende gescheitert sein, mag er durch seine unmäßige Paarung von Banalität und Verwerflichkeit der Geschichtswissenschaft auch als Grenzfall ihrer Disziplin vorkommen und mag endlich jener totale Protest ihm die Chance echten Uberlebens als lebendige Erinnerung und politische Tradition verwehrt haben, weil wohl kaum zureichend historische Notwendigkeit Ziele und Mittel Hitlerscher Politik in ihrer Radikalität des Prinzipiellen und des Praktischen zu rechtfertigen vermag.

Hitler aber steht nach der Lektüre der Festschen Biographie als ein politisches Handeln und menschliches $\mathrm{Maß}$ entweder unterbietendes oder überziehendes Phänomen 
der Weltgeschichte vor uns, von dem bereits Otto Hintze sagte: „Dieser Mensch gehört ja eigentlich gar nicht zu unserer Rasse. Da ist etwas ganz Fremdes an ihm, etwas wie eine sonst ausgestorbene Urrasse, die völlig amoralisch noch geartet ist. «

Demgegenüber vermittelt die von Fest verfaßte Einleitung zu einem 1968 erschienenen, 1975 wieder aufgelegten Bildband über Adolf Hitler. Gesichter eines Diktators ${ }^{24}$ einen Eindruck von Hitlers Persönlichkeit und Politik, den der Autor heute wohl selber korrigieren würde, wenn man seine Uberlegungen über die Funktionalität der "Judenfrage« im Essay und über die Autonomie der Rassenpolitik Hitlers in seinem großen Werk miteinander vergleicht.

\section{David Irvings Beitrag über die Kriegsjahre}

Gänzlich verschieden von Fests Hitler-Biographie nimmt sich das Buch von David Irving ${ }^{25}$ über "Hitler und seine Feldherren « aus. Es handelt sich dabei um einen biographischen Versuch über Hitlers Persönlichkeit und Politik während der Jahre 1939-1945, der aufgrund zahlreicher, bislang unbekannter Details Beachtung verdient, als kompositorische Leistung dagegen nicht überzeugen kann. Denn es finden sich banale Nebensächlichkeiten neben Ergebnissen, die die historische Forschung beschäftigen werden. Imponierend ist die große Zahl bislang unerschlossener Quellen z.B. in Form von Tagebüchern ehemals führender Diplomaten und Generäle, mit denen Irving die Forschung zumindest auszugsweise bekannt macht. Unter ihnen ragt besonders die Benutzung des bisher unbekannten Tagebuches des „Verbindungsmannes « $z$ wischen Ribbentrop und Hitler im Führerhauptquartier, Walter Hewel, hervor. Es wäre nützlich gewesen, wenn Irving im Anhang seines Buches ein wenig systematischer, als dies in der Einleitung und - nicht gerade sehr übersichtlich - im Anmerkungsteil geschehen ist, die benutzten Quellen aufgeführt hätte und wenn sie schon recht bald der Forschung für eine detaillierte Uberprüfung zur Verfügung stehen würden. Mißtrauisch äußert sich der Autor dagegen über den Wert zahlreicher, der Historiographie schon lange bekannter und von ihr benutzter Quellen. Die Fragwürdigkeit der Ciano-Tagebücher (oder neuerdings des Engel-Tagebuches) sind jedoch der zeitgeschichtlichen Forschung keineswegs entgangen. Alles in allem übertreibt es der britische Autor wohl mit seinen Vorbehalten gegenüber allen bisher erarbeiteten Ergebnissen der einschlägigen Geschichtswissenschaft. Wenn er es in den Fußnoten auch weitgehend vermeidet, sich auf einschlägige Sekundärliteratur zu beziehen, so läßt der Gang seiner Argumentation doch immer wieder deutlich werden, daß er z. B. dem großen Werk von Andreas Hillgruber über "Hitlers Strategie « weit mehr verpflichtet ist, als dies bei einer Durchsicht des Anmerkungsapparates deutlich wird. Dennoch: Irvings Buch ist eine Fundgrube neu erschlossener Materialien, die die Forschung insbesondere auch die militärhistorische Forschung - dankbar und kritisch zur Kenntnis nehmen wird. Darüber hinaus aber bietet die Darstellung bruchstückhaft über annähernd 900 Seiten verstreut und leider nicht durch zusammenhängend gestaltete sowie systematisch reflektierende Kapitel gebunden, die vor dem Hintergrund des "alten « Forschungsstandes das "Neue « der Irvingschen Uberlegungen sichtbar machen könnten, bemerkenswerte, wenn auch gewiß bestreitbare Einsichten und Thesen, mit denen sich die Geschichtsschreibung zu beschäftigen haben wird:

1. Generell ist wohl die Tendenz des Autors unübersehbar, dem heute in Ost und West anerkannten Resultat der Weltkriegsforschung, wonach auf dem europäischen Schauplatz des Zweiten Weltkrieges die Hauptfront in Rußland gelegen habe, die Ansicht entgegenzuhalten, eine welch große Bedeutung Hitler der Mittelmeerkriegführung der "Achsenmächte « beigemessen habe - wobei zu fragen wäre, ob hierbei von Irvings Seite aus nicht Jodls Uberlegungen zur »Peripheriestrategie " mit Hitlers davon abweichender Gedankenbildung verwechselt werden. Dementsprechend mißt Irving dem 
anglo-amerikanischen Luftkrieg gegen das Deutsche Reich den "Stellenwert» jener "Zweiten Front ${ }^{26}$ bei, die Stalin bis zum Sommer 1944 vergeblich forderte. Man kann sich des Eindrucks nicht erwehren, als sollte damit der britische (und amerikanische) Anteil am kontinentaleuropäischen Krieg gegenüber der russischen Leistung aufgewertet werden.

2. Was die Behandlung des "Faktors England « in Hitlers Kalkül während der Weltkriegsjahre - insbesondere im Zeitraum 1940-1941 - betrifft, so unterstreicht Irving mit z. T. neuen Materialien überzeugend die bekannte These, daß Hitler stets und vergleichsweise "großzügig“ zum Bündnis mit Großbritannien bereit war. Damit relativiert er das unlängst von Bernd Martin vorgetragene Resultat ${ }^{27}$, demzufolge der Diktator nach dem siegreichen Frankreichfeldzug auch mit Großbritannien zumindest nicht mehr gleichberechtigt habe verhandeln wollen, sondern darauf gewartet habe, bis die Briten "gekrochen « kämen.

3. Neues Schlaglicht auf die deutsche Japanpolitik im Zweiten Weltkrieg könnte werfen, was Irving über Hitlers entsprechende Uberlegungen und Ausführungen bemerkt. Offensichtlich gedachte der deutsche Diktator, Japan während gewisser Phasen des Krieges aus dem Ringen herauszuhalten und war in anderen Zeitabschnitten daran interessiert, Tokio nicht nur in einen pazifischen Krieg zu verwickeln, sondern es sogar am russischen Feldzug teilnehmen zu lassen. So betont Irving, daß Hitler im Zeichen des als sicher angesehenen Sieges über die Sowjetunion im Juli 1941 Japan an der Liquidation der russischen "Konkursmasse " zu beteiligen vorhatte, während er dem ostasiatischen Partner bis dahin allein die Aufgabe zuweisen wollte, durch seine Präsenz im Pazifik die USA zu neutralisieren. Uber die Darstellung von David Irving hinaus gilt es in diesem Zusammenhang jedoch zu klären, was Hitler mit einer solchen Beteiligung Japans letztlich im Schilde führte. Dabei wäre auf Andreas Hillgrubers Interpretation des Hitler-Oshima-Gespräches vom 14. Juli 1941 und die darin zum Vorschein kommende offensive Zielsetzung des Diktators gegenüber den Vereinigten Staaten von Amerika einzugehen ${ }^{28}$. Nach dem Scheitern des russischen Feldzuges allerdings trat Hitler (bis zum Jahresbeginn 1943) nicht mehr dafür ein, Japan am Krieg gegen Stalin teilnehmen zu lassen. Interessant ist in diesem, auch der bisherigen Forschung durchaus bekannten Zusammenhang die von Irving gelieferte Erklärung für das vom Diktator betriebene Fernbleiben Tokios vom russischen Kriegsschauplatz. In Etzdorfs Worten vom 3. November 1941 nimmt sich Hitlers Motiv nämlich so aus: "Führer ist am Kriegseintritt Japans nicht so besonders gelegen; würde nur Frieden erschweren. «(S. 337-338)

4. In Verbindung mit Hitlers Japanpolitik ist sein Verhältnis zu den Vereinigten Staaten von Amerika zu betrachten. Völlig zutreffend betont Irving die generell defensive Zielsetzung des Deutschen Reiches gegenüber den USA in der ersten Hälfte des Krieges, ohne sich jedoch mit weiteren Interpretationen der deutschen Amerikapolitik im Weltkrieg auseinanderzusetzen, die die Forschung inzwischen vorgelegt hat. Zu überlegen wäre nämlich, ob Hitler nicht im Sinne der eben angeführten Auffassung von Hillgruber in den Wochen des Siegesrausches im Sommer 1941 und in charakteristischer Komprimierung seines im Blick auf die USA ursprünglich weitgefaßten Zeitplanes mit Angriffsabsichten gegen Amerika umging. Leider setzt Irving sich in diesem Punkt nicht mit Hitlers Äußerung gegenüber General Oshima am 14. Juli 1941 auseinander, die lautet: "Amerika drücke in seinem neuen imperialistischen Geist mal auf den europäischen, mal auf den asiatischen Lebensraum. Von uns aus gesehen drohe im Westen Rußland, im Osten Amerika. Daher sei er der Meinung, daß wir sie gemeinsam vernichten müßten. Es gebe im Völkerleben Aufgaben, die hart seien. Man könne diese Aufgaben nicht dadurch lösen, daß man sich ihnen verschließt und sich auf einen späteren Zeitpunkt verläßt. « ${ }^{29} \mathrm{Ja}$, darüber hinaus müßte in solchem Zusammenhang 
auch die kürzlich von Norman Rich ${ }^{30}$ gelieferte Interpretation der Amerikapolitik Hitlers in jener Zeit erörtert werden, zumal ihr in der noch nicht veröffentlichten Dissertation von Jochen Thies ${ }^{31}$ über »Hitlers Endziele « zugestimmt wird:Demzufolge hat Hitler 1939-1941 eine vorläufig defensive Position bezogen, die es ihm erlauben sollte, nach einer Eroberung des autarken und blockadefesten Kontinentalimperiums den Vereinigten Staaten von Amerika in schier unbesiegbarer Stellung Paroli zu bieten und die USA von seinem europäischen "Herzland « aus durch wirtschaftliche Maßnahmen größten Stils an das germanische Weltreich heranzuziehen. Möglicherweise trifft diese Erklärungsvariante der deutschen Amerikapolitik im Zweiten Weltkrieg für die Zeit nach dem Scheitern des Unternehmens "Barbarossa (November/Dezember 1941) Hitlers Gedankenbildung, während er im Sommer 1941 davon abweichende Überlegungen angestellt haben könnte.

Zweifellos müssen die deutsch-amerikanischen Beziehungen in diesem kritischen Zeitraum der Weltgeschichte noch einmal neu durchdacht werden - nicht zuletzt unter dem Gesichtspunkt des von Bernd Martin vorgetragenen Gedankens ${ }^{32}$, daß Präsident Roosevelt sich wohl schon recht früh als der entscheidende Gegenspieler Hitlers empfand und darauf bedacht war, sowohl das britische Empire als auch das Deutsche Reich, die sich im europäischen Krieg gegenseitig zerfleischten, während die USA noch in der Neutralität verharrten, zu beerben und Amerika zur wirtschaftlich und politisch dominierenden Macht der Welt heranzuführen.

5. Damit kommen wir zu den interessantesten Partien des Buches. Sie behandeln über Seiten verstreut (wichtig sind z.B. S. 276-277, S. 296-297, S. 329 mit S. 792, S. 395, S. 482-483, S. 529 u. S. 854 Anmerkung 4) die nationalsozialistische Judenpolitik im Zweiten Weltkrieg. Angesichts der Brisanz mancher Bemerkungen des Autors wäre man wohl für ein zusammenfassendes Kapitel zu diesem Problem dankbar gewesen, aus dem klar hervorgehen könnte, welche Interpretation Irving diesem Untersuchungsobjekt gegenüber vorschlägt. Eingeräumt sei dabei, daß der Autor sich offensichtlich mit der vorliegenden deutschen Ausgabe seines Werkes nicht identifizieren möchte, wie man den Andeutungen einer Rezension über das Buch entnehmen kann, die Andreas Hillgruber in der "Frankfurter Allgemeinen Zeitung " veröffentlichte und in der es heißt ${ }^{33}$ : „Der eigenwillige britische Autor hat sich von seinem Werk - genauer: von dieser deutschen Ausgabe - mit Informationen an Historiker, deren Interesse an seiner Arbeit ihm bekannt war (darunter den Rezensenten) distanziert, weil das Manuskript vom Verlag ohne sein Wissen um den ersten Teil und um einige Partien gekürzt worden sei, die dem Verfasser substantiell wichtig erschienen.*

Was immer sich hinter diesen Vorbehalten verbergen mag, vorab ist dies festzuhalten: Die Forschung betont bisher einerseits die Intentionalität der Entscheidung Hitlers als ausschlaggebend für die Vernichtung der Juden (Jäckel; Hillgruber ${ }^{34}$ ) und akzentuiert andererseits das funktionale Element des Entschlusses (Adam; Rich ${ }^{35}$ ), wonach der Schritt zur Vernichtung durch die Notwendigkeit zu überstürzter Improvisation angesichts des für eine Aussiedlung fehlenden Territoriums ausgelöst worden sei. Während Rich und Adam zu dem Ergebnis kommen, Hitlers Entschluß zur systematischen, technisch durchgeführten Vernichtung auf den Herbst/Winter 1941, also auf den Zeitpunkt zu datieren, zu dem das Unternehmen "Barbarossa « als gescheitert galt, geht Andreas Hillgruber - ebenso wie Werner Maser ${ }^{36}$ - davon aus, daß Hitlers Entscheidung zur physischen »Endlösung im Frühjahr/Sommer 1941 fiel, also zu dem Zeitpunkt, als Hitler an einen siegreichen und raschen Verlauf des Rußlandfeldzuges glaubte. Den Ưbergang von der Phase der gegen alle Juden in den eroberten Gebieten der Sowjetunion gerichteten, am 22. Juni 1941 einsetzenden Mordaktionen der Himmlerschen Einsatzgruppen zur Phase der technisch betriebenen Liquidation, wie sie dann vom Jahresende 1941 an eingeleitet wurde, qualifiziert Hillgruber dabei als 
eine quantitative Steigerung, die letztlich auf den früh gefaßten Entschluß Hitlers zurückgeführt wird. Adam und Rich dagegen möchten zwischen der physischen Vernichtung der ersten Phase sowie der technischen "Endlösung " der zweiten Phase offensichtlich qualitativ unterscheiden, ohne jedoch den "Stellenwert " der bereits in Polen und danach - gesteigert und ausgeweitet - in Rußland praktizierten Liquidationen im Rahmen nationalsozialistischer Judenpolitik ausführlich genug zu bestimmen. David Irving setzt sich nun seinerseits mit der von Hitler lange Zeit erwogenen Deportationsidee gegenüber den Juden (»territoriale Endlösung ") ausführlicher auseinander und versucht, sie deutlich von der Praxis der physischen Liquidation abzusetzen. Er berichtet davon, der Diktator habe erwogen, die jüdische Bevölkerung des Reiches und sodann die des eroberten Europas zuerst nach Palästina, dann nach Madagaskar und endlich in den "Ostraum " abzuschieben. "Was meinte Hitler genau, wenn er sagte: >Nach dem Osten«? Am 20. Juni (1941) hatte Rosenberg in einem Vortrag vor Canaris, Heydrich und einer großen Schar anderer führender Partei- und Wehrmachtangehöriger enthüllt, daß Weißruthenien als Reservation für sunerwünschte und asoziale Elementer angesehen werde, die aus dem deutschen Herrschaftsbereich dorthin abtransportiert werden sollten. Die Hauptstadt von Weißruthenien ist Minsk. Sollte hier das neue Israel entstehen, oder wählte Hitler, wenn er ,Osten، sagte, eine bewußt allgemein gehaltene Formulierung, deren präzisere Definition lauten würde: Elend, Vergasen, Ausrottung? Die uns zur Verfügung stehenden Dokumente geben keine Auskunft, und es ist nicht erlaubt, zu spekulieren. «(S. 277) Nun sind wir schon eingehender, als Irving es darstellt, über die Bedingungen unterrichtet, denen das zur Deportation in den eroberten Ostraum vorgesehene europäische Judentum ausgesetzt werden sollte, da die »Vorläufigen Richtlinien für die Behandlung der Juden im Reichskommissariat Ostland " vom 13. August 1941 - sie basieren auf den im Reichssicherheitshauptamt im Juli oder August 1941 entstandenen "Richtlinien für die Behandlung der Judenfrage « - bekannt sind.

Insgesamt betont Irving die Tatsache, daß kein schriftlich formulierter Befehl Hitlers zur "Endlösung" aufzufinden sei, bewertet dabei das Moment der systematisch und bewußt betriebenen Verschleierung des Genocids wohl zu gering und vernachlässigt es im übrigen, die nationalsozialistische Judenpolitik von ihren Anfängen bis zu ihrem Ende in eine historische Perspektive zu rücken. Sie könnte dazu geeignet sein, die stete Steigerung der "Maßnahmen« des Regimes gegen die jüdische Bevölkerung vor dem Hintergrund des eben nicht nur instrumentalen Antisemitismus Hitlers darzustellen. Dagegen hat es den Anschein, als gehe Irving davon aus, Hitler habe bis 1943 an dem Deportationsplan festgehalten und erst danach die bereits unter Himmlers Leitung angelaufene Vernichtung des Judentums befürwortet, ohne daß wir erführen, warum sich der Diktator gerade 1943 zur Praxis der angeblich von der SS weitgehend selbständig veranlaßten Lösung bekannt habe: „In diesem Stadium “, so heißt es bei Irving im Hinblick auf das im Juli 1941 zwischen Hitler und dem kroatischen Marschall Kvaternik stattgefundene Gespräch, »betrachtete also Hitler die Juden noch als besondere Kategorie, getrennt von, zum Beispiel, Gewohnheitsverbrechern - den Unverbesserlichen, den rasozialen Elementen`, die eine Gefahr für jedes Staatsgefüge seien und mit denen man nur eines machen könne: sie vernichten . . . Aber als er dieses Argument das nächste Mal vortrug, im April 1943, warf er die Juden in einen Topf mit dieser Kategorie der ,Schurken«.« (S. 297)

In den mit Ablauf des Unternehmens »Barbarossa « einhergehenden Erschießungsaktionen sieht Irving das Ergebnis langfristiger Planung, ohne auf die Frage nach dem quantitativen oder qualitativen Unterschied zwischen der systematisch betriebenen Liquidation der Juden durch die Einsatzgruppen und der technisch durchgeführten "Endlösung “ durch Verwendung von Gas näher einzugehen: „Bis zum 3. November 
(1941) hatten die Einsatzgruppen 75000 Juden ermordet. Zwingende Anzeichen deuten darauf hin, daß Erschießungsaktionen dieses Ausmaßes lange vor Beginn des Unternehmens Barbarossa geplant worden waren. Während eines Lehrganges für Chefs der Einsatzgruppen und Sonderkommandos, der im Juni in Düben stattfand, hatte Heydrich ausgeführt, daß die Ostjuden das intellektuelle Reservoir des Bolschewismus seien und deshalb, >nach Ansicht des Führers‘, vernichtet werden müßten. Er wiederholte das in einer Rede im Berliner Gestapo-Hauptquartier. Jetzt, im September 1941, besuchte Himmler selbst die Einsatzgruppen und versicherte ihnen, daß er allein, sin Ubereinstimmung mit dem Führer`, verantwortlich sei für die Exekution der Juden. “ (S. 329) Unverständlich bleibt dann aber die in diesem Zusammenhang von Irving applizierte Fußnote (S. 792): „Doch erwähnte Hitler auch seinen treuesten Kollegen gegenüber nichts von einem Judenvernichtungsprogramm. « ${ }^{37}$ Wenn der Diktator bis zum Jahre 1943 nicht vorhatte, die Juden des Reiches, des eroberten Rußlands und sodann des besetzten Gesamteuropas "so oder so « zu vernichten (indirekt auf dem Wege der Deportation, direkt durch Erschießung und Vergasung) und wenn man die entsprechenden Bekenntnisse, z.B. in Hitlers Rede vom 24. Februar 1942 , in der es heißt, "durch diesen Krieg (werde) nicht die arische Menschheit, sondern der Jude ausgerottet werden ${ }^{3 \theta}$, beiseite schiebt, so fragt man sich im Hinblick auf Irvings Argumentation doch, wie es in Hitlers Gedankenbildung zu den von Irving beschriebenen Tötungsaktionen großen Stils im Rahmen des Feldzuges gegen die Sowjetunion kommen konnte. Bei Irving heißt es u. a.: "Hitler selbst war zweifellos die Autorität hinter den Vertreibungsmaßnahmen; zweifelhaft ist, auf wessen Initiative die mörderischen Prozeduren selbst an den Endstationen dieses jammervollen Exodus zurückgingen. " (S. 395)

Es erweckt den Anschein, als halte Irving Himmler für den im Grunde Verantwortlichen für die Judenvernichtung, der auf diesem Gebiet gegenüber dem "Führer« eine von den Intentionen des Diktators abweichende Initiative entwickelt habe. So schreibt Irving in Kritik an Reitlingers Werk über "Die Endlösung«: »Gerald Reitlingers gewichtiges Werk . . . ignoriert auffälligerweise sowohl Himmlers eigene handschriftliche Aufzeichnungen seines Telefonanrufes bei Gestapochef Reinhard Heydrich aus dem Führerbunker in der Wolfsschanze vom 30. November 1941 des Inhalts, daß es keine 'Liquidierung der Juden، geben dürfe, als auch die Massen an dokumentarischen Beweisen, die Hitlers Beziehung zu der biologischen Ausrottung klarstellen, die dennoch folgte. «(S. V) Einige hundert Seiten weiter aber heißt es bei Irving unter Bezug auf Himmlers Gespräch mit Hitler vom November 1941 (S. 482-483): »Himmler wußte, daß Hitler im November 1941 die Verwendung des. Wortes Liquidation ${ }^{39}$ für die abtransportierten Juden verboten hatte. Am 1. April befahl er Kaltenbrunner, dem Chef der SiPo und des SD, den Bericht 'zur Vorlage an den Führer zu kürzen; und wenige Tage später - für den Fall, daß er sich noch nicht deutlich genug ausgedrückt hatte - gab er Anweisung, daß in der Fassung für den Führer >an keiner Stelle von 'Sonderbehandlung der Juden' gesprochen` werden dürfe. Im neuen Text müsse es heißen: >durchgeschleust durch die Lager nach Rußland und nicht: >der Sonderbehandlung zugeführt،. Wie er Kaltenbrunner am 9. April schrieb, werde sich der Bericht in späteren Zeiten gut zu , Tarnungsz wecken eignen: > Das Wichtigste ist mir nach wie vor, daß jetzt an Juden nach dem Osten angefahren wird, was überhaupt nur menschenmöglich ist.«"

Offensichtlich hatte Hitler jede schriftliche Andeutung untersagt, die eine Spur für die Nachwelt legen konnte und auf die Judenvernichtung aufmerksam machen würde eine solche Interpretation des von Irving mitgeteilten Befundes würde sich durchaus mit den bisher bekannten Ergebnissen der Forschung über Hitlers Judenpolitik im Zweiten Weltkrieg vereinbaren lassen. 
Insgesamt gesehen hat Irving Dokumente zutage gefördert, die zu einem Úberdenken des gesamten Untersuchungsgegenstandes der nationalsozialistischen Judenpolitik im Zweiten Weltkrieg anregen. Dabei wäre es wünschenswert, daß der englische Autor einmal im Zusammenhang seine Position zu den anstehenden Fragen beschreiben und dabei über die Publikation von Quellenstücken und über interpretatorische Andeutungen hinausgehen würde.

Angesichts der Bedeutung der durch Irving aufgeworfenen Fragen zur Weltkriegsgeschichte nehmen sich die Korrekturen am bisherigen Forschungsstand minimal aus, die Martin L. van Creveld ${ }^{40}$ in seiner Arbeit über "Hitler's Strategy 1940-1941. The Balkan Clue « vornimmt und darin minutiös die Begebenheiten des deutschen Feldzuges gegen Jugoslawien und Griechenland im Frühjahr 1941 darstellt. Größeres Interesse werden dagegen vielleicht die Bücher von James Douglas-Hamilton ${ }^{41}$ über den "Friedensboten Rudolf Hess und seine Hintermänner « und von Ursula Laack-Michel ${ }^{4}$ über "Albrecht Haushofer und der Nationalsozialismus « finden, die u. a. das Geheimnis des Hess-Fluges nach Schottland vom 10. Mai 1941 zu klären versuchen. Während Hamilton wie auch Eugene $K$. Bird ${ }^{42}$ in seinem "Report « über Hess dazu neigen anzunehmen, der "Stellvertreter des Führers « habe in Kenntnis der politischen Gedankenwelt Hitlers das Abenteuer auf eigene Faust und ohne Wissen des Diktators unternommen, faßt Ursula Laack-Michel ihre gut fundierte gegensätzliche Meinung in dem Satz zusammen: "Der Vorsatz, den Hess möglicherweise erst im Winter 1940/41 faßte, selbst sals Parlamentär aus eigenem Entschluß nach England zu fliegen, und seine Pläne dazu waren Hitler mit größter Wahrscheinlichkeit bekannt. « (S. 215) Sind derlei Detailuntersuchungen dazu geeignet, noch verbliebene Rätsel der Forschung zu lösen, so erscheinen die Hitler-Biographien aus der Feder von James Bunting $^{43}$ und Robert Payne ${ }^{44}$ ebenso wie ein von Alan Wykes ${ }^{45}$ in der ${ }^{3}$ Ballantine Illustrated History of World War II « vorgelegter Bild- und Textband über Hitler kaum der Erwähnung wert zu sein - es sei denn, um auf Fehler aufmerksam zu machen wie den von Payne, der Hitler 1912 einige Monate in England leben läßt. Für den Historiker wenig aufschlußreich liest sich auch das von dem amerikanischen Psychologen Walter C. Langer ${ }^{46}$ im Auftrag des "Office of Strategic Services« im Krieg verfaßte Gutachten über "The Mind of Adolf Hitler «, während die Studie von J. P. Stern ${ }^{47}$ über "Hitler. The Führer and the People« durch erwägenswerte Uberlegungen über das Verhältnis Hitlers zur Masse aus der Fülle der Literatur der "Hitlerwelle " herausragt.

\section{Hitlers Endziele}

Der die Forschung immer wieder beschäftigenden Frage nach Hitlers letzten Zielen, die im Rahmen eines im Juli 1974 von Eberhard Jäckel in Stuttgart veranstalteten Kolloquiums unter dem Titel „Hitlers Endziele - Kontinentalgroßmacht oder Weltherrschaft « mit viel Sach- und Detailkenntnis der einschlägigen Quellen behandelt wurde, hat sich Jochen Thies ${ }^{31}$ in einer von Andreas Hillgruber angeregten und betreuten Freiburger Dissertation zugewandt. Neben der Interpretation der teils neu entdeckten, teils bereits bekannten schriftlichen Zeugnisse, die belegen können, daß Hitler sich bereits seit den 20er Jahren mit dem Gedanken der Weltherrschaft beschäftigt hat, setzt sich Thies fruchtbar mit den architektonischen Herrschaftszeichen des Diktators auseinander. Sie machen anschaulich, daß Hitlers Weltherrschaftsideen seine Gedankenbildung in machtpolitischer und rassischer Hinsicht stets bestimmten.

Ein nicht zuletzt in diesem Zusammenhang bislang immer als dubios angesehenes Dokument, das die globale Zielsetzung des "Führers « zu erkennen gab, sind die jetzt wieder aufgelegten "Gespräche mit Hitler" aus der Feder von Hermann Rauschning ${ }^{48}$. 
Schieder ${ }^{49}$ so weit wie möglich geklärt worden, der das Ergebnis seiner Recherchen so zusammenfaßt: "Rauschnings ,Gespräche mit Hitler` sind kein Quellendokument, von dem man wörtliche und protokollarische Ubberlieferung Hitlerscher Sätze und Sentenzen erwarten darf, so vieles auch darin diesen Erfordernissen entspricht. Es ist ein Dokument, bei dem sich objektive und subjektive Momente verwischen und Wandlungen der Meinung des Autors über seinen Gegenstand mit in diesen Gegenstand eingegangen sind. Sie sind aber ein Dokument von unbezweifelbarem Quellenwert insofern, als sie Deutungen enthalten, die aus unmittelbarer Einsicht erwachsen sind. Einsicht soll hier im doppelten Sinn des Wortes verstanden werden: als die Form der direkten Anschauung und zugleich als das Ergebnis, das aus einer Anschauung durch Nachdenken hervorgeht. «(S. 627)

$\mathrm{Zu}$ den hier behandelten Problemen der Forschung geben die von Lew Besymenski ${ }^{50}$ herausgegebenen mletzten Notizen von Martin Bormann " nichts her, und ein von einem Verfasser namens $K_{a r d e l}{ }^{51}$ unter dem Titel "Adolf Hitler - Begründer Israels « vorgelegtes Buch mit der These, der "Führer « habe als ein "Judenabkömmling " seine eigene Rasse gehaßt und verfolgt, mag dem Sensationsbedürfnis gewisser Leserkreise entgegenkommen. Für die Geschichtswissenschaft aufschlußreich erscheint dagegen Heinrich Himmler. Gebeimreden 1933 bis $1945^{52}$, die teilweise bislang noch nicht veröffentlicht sind.

Vor allem die zwei Tage nach Himmlers berühmter Rede vor den SS-Führern in Posen (4. Okt. 1943) in der gleichen Stadt vor den Reichs- und Gauleitern gehaltene, bisher noch nịcht veröffentlichte Ansprache ist insofern wichtig, als Himmler sich in ihr - wie in der der Forschung schon lange zugänglichen bekannten Posener Rede vom 4. Okt. 1943 - wiederum offen zur Judenpolitik äußert: »Ich bitte Sie, das, was ich Ihnen in diesem Kreise sage, wirklich nur zu hören und nie darüber zu sprechen. Es trat an uns die Frage heran: Wie ist es mit den Frauen und Kindern? - Ich habe mich entschlossen, auch hier eine ganz klare Lösung zu finden. Ich hielt mich nämlich nicht für berechtigt, die Männer auszurotten - sprich also, umzubringen (!) oder umbringen zu lassen und die Rächer in Gestalt der Kinder für unsere Söhne und Enkel groß werden zu lassen. Es mußte der schwere Entschluß gefaßt werden, dieses Volk von der Erde verschwinden zu lassen. " (S. 169) Anders als David Irving, der offensichtlich darum bemüht ist, zu zeigen, Himmler habe in der Behandlung der Juden eigene und von Hitler abweichende Wege beschritten, heißt es in der von Joachim Fest verfaßten Einleitung zu der vorliegenden Edition: "Das historische Material macht jedoch deutlich, daß keine Eigenmacht im Spiel gewesen ist: was in Himmler und der SS zutage trat, war nie etwas anderes als der Vollzug dessen, was Hitler ausdrücklich gewollt hat oder was in der Konsequenz seines Willens lag. Es gab keine Divergenz zwischen den Aktivitäten der SS und der Idee des Regimes. “ (S. 22)

Im Rückblick auf die vorgestellten Ergebnisse der Forschung kann festgestellt werden, daß es geboten scheint, einmal umfassend die dogmatische Seite der Strategie Hitlers, die Rassenpolitik, zu untersuchen. Denn sie war es in hohem, wenn nicht in entscheidendem Maße, die dazu beitrug, die mit ihr eng verbundenen machtpolitischen $\mathrm{Pla}$ nungen, die Weltpolitik des Diktators, zu unterlaufen und zu zerstören. Eine Darstellung der nationalsozialistischen Judenpolitik, des »Euthanasieprogramms und der „Züchtungsmaßnahmen “ des Regimes, die allesamt als Teile der Weltanschauung Hitlers zu begreifen sind und einander komplementär ergänzten, erscheint als dringendes Desiderat der Geschichtswissenschaft. 


\section{Anmerkungen}

1 N. Rich: Hitler's War Aims. Vol. 1: Ideology, the Nazi State, and the course of expansion. New York 1973, S. 11.

2 H. Mommsen: Nationalsozialismus. In: Sowjetsystem und demokratische Gesellschaft. Eine vergleichende Enzyklopädie, hrsg. von C. D. Kernig. Bd 4. Freiburg i.Br., Basel, Wien 1971, Sp. 702.

3 M. Broszat: Soziale Motivation und Führerbindung des Nationalsozialismus. In: VfZG 18 (1970) 409.

4 Ursula Laack-Michel: Albrecht Haushofer und der Nationalsozialismus. Ein Beitrag zur Zeitgeschichte. Stuttgart: Klett 1974. 407 S. (= Kieler Historische Studien. Bd 15.); hier S. 362.

5 Titel einer von Professor J. Joll geleiteten, am 16. 9. 1975 in der British Broadcasting Corporation ausgestrahlten Diskussion (The , Hitlerwelles).

6 Alan Bullock: Hitler. Eine Studie über Tyrannei. Vollständig überarbeitete Neuausgabe unter Mitarbeit von Helmut Teufel. Aus dem Englischen übertragen von Wilhelm und Modeste Pferdekamp. Ubersetzung neuer Textteile unter Mitarbeit von Margret Wand. Düsseldorf: Droste 1971. XII, 886 S.

7 Helga Grebing: Der Nationalsozialismus. Ursprung und Wesen. 18. gegenüber der 17. unveränderte Auflage. München, Wien: Olzog 1974. 160 S. (= Geschichte und Staat. Bd 103.)

B Hugh R. Trevor-Roper: Hitlers letzte Tage. Ungekürzte Ausgabe. Ubersetzt von Joseph Kalmer. 3. Auflage. Die Einleitung von Gisela Breiting-Wolfsholz übertragen. Frankfurt a. M., Berlin: Ullstein 1973. 238 S. (= Ullstein-Buch. Nr. 525.)

9 Gert Kalow: Hitler - das deutsche Trauma. München: Piper 1974. 150 S. (= Serie Piper. 114.)

10 Siehe dazu M. Cowling: The Impact of Hitler. British politics and British policy 1933-1940. Cambridge 1975.

11 Werner Maser: Adolf Hitler. Legende, Mythos, Wirklichkeit. 6., vom Autor (durch Eva Brauns Tagebuch) ergänzte Auflage. Eßlingen: Bechtle 1974. 628 S.

12 Werner Maser: Der Sturm auf die Republik. Frühgeschichte der NSDAP. Revidierte Neuausgabe von "Die Frühgeschichte der NSDAP». Stuttgart: Deutsche Verlags-Anstalt 1973. 524 S.; die Revisionen sind kaum erheblich.

13 A. Tyrell: Vom "Trommler« zum "Führer«. Der Wandel von Hitlers Selbstverständnis zwischen 1919 und 1924 und die Entwicklung der NSDAP. München 1975.

14 Werner Maser. Hitlers Briefe und Notizen. Sein Weltbild in handschriftlichen Dokumenten. 2. Auflage. Düsseldorf, Wien: Econ 1973. 397 S

15 H. Auerbach: Hitlers Handschrift und Masers Lesefehler. Eine notwendige Berichtigung. In: VfZG 21 (1975) $334 \mathrm{ff}$.

16 Werner Maser: Adolf Hitler. Mein Kampf. Fahrplan eines Welteroberers. Geschichte. Auszüge. Kommentare. Eßlingen: Bechtle 1974. 454 S.

17 Christian Zentner: Adolf Hitler. Mein Kampf. Eine kommentierte Auswahl. 2. Auflage. München: List 1974. $255 \mathrm{~S}$

18 Mein Schüler Hitler. Das Tagebuch seines Lehrers Paul Devrient. Bearbeitet und herausgegeben von Werner Maser. Pfaffenhofen/Ilm: Ilmgau-Verlag 1975. 303 S.

19 Haben Sie Hitler gesehen? Deutsche Antworten. Gesammelt von Walter Kempowski. Nachwort von Sebastian Haffner. München: Hanser 1973. 118 S. (= Reihe Hanser. 113.)

20 Philipp W. Fabry: Mutmaßungen über Hitler. Urteile von Zeitgenossen. Düsseldorf: Droste 1969. $265 \mathrm{~S}$.

21 F. P. Reck-Malleczewen: Tagebuch eines Verzweifelten. Zeugnis einer inneren Emigration. Frankfurt a. M., Hamburg 1971, S. 128.

22 C. F. v. Weizsäcker: Zum 20. Juli. In: Informationen für die Truppe. Hefte für politische Bildung und Innere Führung. 1975, H. 5, S. 20 ff.

23 Joachim C. Fest: Hitler. Eine Biographie. Frankfurt a. M., Berlin, Wien: Propyläen 1973. 1190 S.

24 Adolf Hitler. Gesichter eines Diktators. Eine Bilddokumentation. Herausgegeben von Jochen Lang Joachim Fest zeichnet ein Psychogramm des Diktators Adolf Hitler. Die Fotos stellte das Zeitgeschichtliche Bildarchiv Heinrich Hoffmann zur Verfügung. München: Herbig 1975. 16 S., 80 Abb. auf ungez. Seiten.

25 David Irving: Hitler und seine Feldherren. Aus dem Englischen von Erwin Duncker. Bilddokumentation: Christian Röthlingshöfer. Frankfurt a. M., Berlin, Wien: Ullstein 1975. X, 885 S.

26 Vgl. dazu A. Hillgruber: Das Problem der "Zweiten Front* in Europa 1941-1944. In: Seemacht und Geschichte. Festschrift z. 80. Geburtstag von Friedrich Ruge. Bonn-Bad Godesberg 1975, S. 141.

27 B. Martin: Friedensinitiativen und Machtpolitik im Zweiten Weltkrieg 1939-1942. Düsseldorf 1974, S. $300 \mathrm{f}$. (zit. Martin); s. die Bespr. in diesem Bande, S. $259 \mathrm{ff}$.

28 A. Hillgruber: Der Faktor Amerika in Hitlers Strategie 1938-1941. In: Aus Politik und Zeitgeschichte. Beilage zur Wochenzeitung Das Parlament. 1966, B 19, S. 17.

29 Staatsmänner und Diplomaten bei Hitler. Vertrauliche Aufzeichnungen über Unterredungen mit Vertretern des Auslandes. Hrsg. und erl. von A. Hillgruber. T.2: 1942-1944. Frankfurt a. M. 1970, S. 549; s. die Besprechung des Bandes in MGM 9 (1971) 270.

30 N. Rich: Hitler's War Aims. Vol. 2: The Establishment of the New Order. New York 1974, S. 418 (zit. Rich).

31 Jochen Thies: Hitlers "Endziele«. Freiburg i. Br., Phil. Diss. 1975. 302 Bl. Indessen im Buchhandel u. d. T. Architekt der Weltherrschaft. Die «Endziele* Hitlers. Düsseldorf: Droste 1976. 221 Seiten.

32 Martin, S. 132 ff. u. $207 \mathrm{ff}$. 
33 Frankfurter Allgemeine Zeitung v. 17. 7. 1975, S. 7.

34 E. Jäckel: Hitlers Weltanschauung. Entwurf einer Herrsch aft. Tübingen 1969, S. 58 ff. (zit. Jäckel); A. Hillgruber: Die "Endlösung* und das deutsche Ostimperium als Kernstück des rassenideologischen Programms des Nationalsozialismus. In: VfZG 20 (1972) 142.

35 U. D. Adam: Judenpolitik im Dritten Reich. Düsseldorf 1972, S. 312 f. (Das Werk ist besprochen in MGM 18 (1975) 169); Rich, Vol. 2, S. 101 f.

36 Siehe S. 211.

37 Im Original hervorgehoben.

38 Zit. nach Jäckel, S. 81.

39 Im Original nicht hervorgehoben.

40 Martin L. van Creveld: Hitler's Strategy 1940-1941. The Balkan clue. London: Cambridge University Press 1973. X, 248 S. (= International Studies.)

41 James Douglas-Hamilton: Geheimflug nach England. Der „Friedensbote* Rudolf Heß und seine Hintermänner. Aus dem Englischen übersetzt von Dieter Flamm. Mit einem Vorwort von Alan Bullock und einem Nachwort für die deutsche Ausgabe von Hans-Adolf Jacobsen. 2. Auflage. Düsseldorf: Droste 1973. 222 S.

42 Eugene K. Bird: Hess. Der „Stellvertreter des Führers«. Englandflug und britische Gefangenschaft. Nümberg und Spandau. Ins Deutsche übertragen von Heinrich Graf v. Einsiedel. München, Wien, Basel: Desch 1974. 310 S.

43 James Bunting: Adolf Hitler. Folkestone, Kent: Bailey \& Swinfen 1973. 157 S

44 Robert Payne: The Life and death of Adolf Hitler. New York, Washington: Praeger 1973. XIII, 623 S.

45 Alan Wykes: Hitler. London: Pan Books 1973. 160 S. (= The Pan/Ballantine Illustrated History of World War II.) (= War Leader. Book No. 1.)

46 Walter C. Langer: The Mind of Adolf Hitler. The secret wartime report. Foreword by William L. Langer. Afterword by Robert G. L. Waite. New York, N. Y.: The New American Library 1973. IX, 286 S. (= Signet Book. 451.)

47 J. P. Stem: Hitler. The Führer and the people. Glasgow: Collins 1975. 254 S.

48 Hermann Rauschning: Gespräche mit Hitler. Zürich: Europaverlag 1973. 278 S.

49 Theodor Schieder: Hermann Rauschnings »Gespräche mit Hitler« als Geschichtsquelle. Opladen: Westdeutscher Verlag 1972. 91 S. (= Rheinisch-Westfälische Akademie der Wissenschaften. Geisteswissenschaften. Vorträge. G 178.)

so Lew Besymenski: Die letzten Notizen von Martin Bormann. Ein Dokument und sein Verfasser. Aus dem Russischen übertragen von Reinhild Holler. Stuttgart: Deutsche Verlags-Anstalt 1974. 344 S.

51 Hennecke Kardel: Adolf Hitler - Begründer Israels. Genf: Marva 1974. 267 S.

52 Heinrich Himmler. Geheimreden 1933 bis 1945 und andere Ansprachen. Hrsg. von Bradley F. Smith und Agnes F. Peterson mit einer Einführung von Joachim C. Fest. Die Ubersetzung des Essays, der Anmerkungen und Zwischentexte aus dem Englischen besorgten Gerhard Lawrentz und Dietmar Staffelt. Frankfurt a. M., Berlin, Wien: Propyläen 1974. 319 S. 